\title{
Preliminary damage survey of school buildings and proposed plan for reconstruction of school buildings after 2015 Gorkha earthquake in Nepal
}

Youb Raj Paudyal ( $\nabla$ youbrajpaudyal@gmail.com )

National Reconstruction Authority, Government of Nepal

Netra Prakash Bhandary

Ehime University

Ryuichi Yatabe

Ehime University

\section{Research}

Keywords: 2015 Gorkha earthquake, school building, damage assessment, reconstruction plan

Posted Date: April 17th, 2020

DOI: https://doi.org/10.21203/rs.3.rs-21671/v1

License: (c) (1) This work is licensed under a Creative Commons Attribution 4.0 International License.

Read Full License 


\section{Abstract}

The 2015 Gorkha Earthquake ( $\mathrm{Mw}=7.8)$ in Nepal has devastated about 9,000 schools. The majority of damage was conceived in the peripheral districts of the Kathmandu valley. Damage distribution in the most-affected 14 districts shows that previous construction practices were an important determent for the intensity of the damage observed across these districts. The use of improper construction materials, lack of construction supervision and non-compliance with existing building codes during design and construction contributed to most of the school buildings to be severely or fully damaged. In addition to the physical damage to infrastructure, there is a significant psychological impact in terms of the effect that the disaster had on the mental health of on the school-going children, their parents and teachers within the affected areas. Preliminary damage assessment results show that in the most-affected districts, about $86 \%$ schools have been affected by the earthquakes and about one million students have been or still are out of schools for a longer period of time as a result of this. Preliminary data shows that about $30 \%$ classrooms are collapsed, about $13 \%$ classrooms are major damaged, and about $17 \%$ are minor damaged with in the most-affected 14 districts. This evidences of losses and damages from the earthquake provides an opportunity to learn lessons for future preparedness to encounter the challenge of disaster. This paper attempts to identify the needs to be addressed for the reconstruction of school buildings after 2015 Gorkha Earthquake in Nepal.

\section{Introduction}

Nepal lies in the central part of the Himalaya and occupies central one-third of the Himalayan Arc (i.e., about $2400 \mathrm{~km}$ ), which is formed by the collision of Indian and Eurasian plates that started about 55 million years ago (Molnar 1986). Various research studies mention that the Himalayan Zone contracts due to the subduction of the Indian plate underneath the Eurasian plate at an annual rate of 16-18 mm (Bilham and Szeliga 2008). This particular process has increased the earthquake hazard in Nepal and the Himalayan Region. Over the past 120 years, the Himalayan Arc has experienced Six major earthquakes; in 1897 (Silong Earthquake, Mw = 8.03, Death-1500), 1905 (Kangra Earthquake, Mw = 7.79, Death- 20,000), 1934 (Nepal Bihar Earthquake, Mw = 8.1, Death-16,000), 1950 (Asham-Tibet Earthquake, Mw = 8,44, Death- 30,000, 2005 (Kasmir Earthquake, Mw = 7.6, Death-75,000), and 2015 (Gorkha Earthquake, $\mathrm{Mw}=$ 7.8, Death-8857) (Bilham et al. 1995; MoHA 2015; Pandey et al. 1995; Paudyal et al. 2012), and damaged many parts of Nepal, Pakistan, and India. It has been reported that 1934 Bihar-Nepal Earthquake (Mw = 8.1) caused heavy damaged in many historic urban areas of Nepal, such as Kathmandu, Biratnagar, and Dharan. The maximum intensity recorded in the valley was X in MMI scale (Pandey and Molnar 1988). About 8,519 people were killed and about 200,000 houses including schools, temples and historic buildings were destroyed in Nepal in this earthquake disaster (Pandey and Molnar 1988).

The recent 2015 Gorkha Earthquake, Mw $=7.8$ with its epicenter located about $140 \mathrm{~km}$ west of Kathmandu Valley, produces strong shaking in central Nepal and causes massive damages. 14 districts, in the central and western region (Fig. 1) out of 75 districts, were the most affected. About 9,000 people were killed, about 600,000 houses and about 9,000 school buildings were destroyed in Nepal by this 
earthquake. The total damage and loss in the education sector is estimated at NPR 31.3 billion (PDNA 2015). More than $80 \%$ of this loss has occurred in the 14 most-affected districts (Fig. 1). The damage to educational infrastructures and losses in physical assets are estimated at NPR 28 billion (PDNA 2015). About $86 \%$ of the total school buildings in 14 most-affected districts were destroyed by the earthquake. The devastation in 14 most-affected districts caused by the 2015 Gorkha earthquake in particular shows that previous construction practices were an important determent for the intensity of the damage observed across these districts. The use of improper construction materials, lack of construction supervision and non-compliance with existing building codes during design and construction contributed to most of the school buildings to be severely or fully damaged. In addition to the physical damage to infrastructure, there is a significant psychological impact in terms of the effect that the disaster had on the mental health of on the school-going children, their parents and teachers within the affected areas.

Due to the geological and topographical features of Nepal, many school buildings had suffered from different kind of disaster especially from earthquakes, floods and landslides. A main determent of the vulnerability of schools seems to be the location of schools and extent to which construction technology and materials have been used during construction. Most of the schools are located near the bank of rivers, near landslide prone areas, at the top of hills and near forests. The majority of the schools buildings, including those constructed in recent years, have not been constructed in compliance with existing building codes that are to be observed during the design and construction phase. Moreover, they were often found not to have been constructed with technical advice from engineers during design and construction. A majority of the school buildings in hill and mountains regions are constructed using a load-bearing stone masonry wall system and brick masonry in flat terrains of the Terai. Tread of cementbased masonry wall construction and reinforce cement concrete (RCC) construction is increasing in urban and semi-urban areas. Mud is used as mortar in most cases for the construction of the stone and brick masonry wall in some areas of Terai, mostly in hill and mountain areas although cement-based construction is prevalent in urban and semi-urban areas. Despite the high risk of earthquake disasters, the school infrastructure construction practice in Nepal has largely ignored the issues of structural safety, especially in terms of structural design and construction. The high vulnerability of schools was evidenced during the recent 2015 Gorkha Nepal earthquake $(\mathrm{Mw}=7.8)$ in Nepal; thirty-six thousand classrooms were destroyed in this event, which luckily took place during non-school hours. Massive damage to the school infrastructure disrupted the affected community's approximately one million children, who were not able to properly attend schools for several months after the event (PDNA 2015; DOE 2015).

There is growing consensus among stakeholders that public infrastructure (schools) in Nepal is particularly susceptible to seismic risk. In 1998 a study conducted by the National Society for Earthquake Technology (NSET) revealed that one third of all schools in Kathmandu valley, Nepal were structurally dilapidated and needed to be demolished and rebuilt. Furthermore, as high as 60 percent of public school buildings in Kathmandu valley were vulnerable under normal operating conditions (NSET 2000; Dixit et al. 2015). The study highlighted a compelling need for developing and implementing an effective, integrated, and "ground-real" strategy for radically improving the seismic safety of schools all across the country. 
Thus, launching of the school earthquake safety program in Nepal is both timely and relevant. This however requires immense financial resource, in order to enable Nepal to protect the life of large number of school children. Due to the geographical condition of the country, the methodology for program implementation will has to be developed on a case to case scenario and as such will be challenging for the Government of Nepal to develop appropriate methodology to address the geographical diversity across regions. There is also an urgent need to explore innovative ideas and methodologies for the post 2015 disaster school reconstruction program to be implemented with minimum cost without compromising structural safety of school buildings.

In this study, data collection of damage school buildings is done in different 14 most-affected districts of Nepal using a standard form developed after wider consultation with different stake holders under Department of Education, Ministry of Education, Nepal. Compiling and analyzing the data were done and results are presented in the graphs. The paper introduces some initiatives that need to be undertaken for the reconstruction of school buildings and finally, an attempt has been made to develop a plan for the reconstruction of school building after 2015 Gorkha earthquake in Nepal.

\section{Importance Of Schools}

School buildings are critical infrastructure not only because children study in them, but also because they are used as an emergency shelters. So, they should be safe from any kind of disasters. Many research works have highlighted that the school-based disaster education programs were useful for increasing community disaster preparedness and the effect of student's participation in disaster education programs is always promising, and the output have been very effective (Parajuli 2020; Patel 2007; Nathe 2000; Ronan et al. 2010; Shaw et al. 2004; Tuladhar et al. 2014; Tuladhar et al. 2015).

Since schools are typically well distributed throughout communities and districts, they are an ideal location for homeless shelters, medical clinics, and other emergency functions. Schools perform important role to build and sustain regional society (Ando et al. 2007). School children and teachers are the main conveyer of the message to the community. Awareness raising at school level is easier for it is a learning center to the community. Almost all households have representatives at schools, so knowledge on disaster management is easily transferred to community. Students are by default engaged in teachinglearning processes and as such could be updated regarding knowledge and try to implement immediately, making schools a perfect medium to be used as disaster risk reduction knowledge hub and dissemination mediums. Furthermore, training programs, for example, safe construction to masons, could be conducted during construction of schools, making it to be easily replicated in the society. Trained masons are the useful resources for the construction of earthquake safe buildings in the community.

Realizing the importance of school earthquake safety, the United Nations International Strategy for Disaster Reduction (UN-ISDR) launched a campaign in 2006 on the theme of "Disaster Risk Reduction Begins at School". Furthermore, the role of knowledge, innovation, and education to build a culture of 
safety and resilience has been underscored as one of the five priorities for action in the Hyogo Framework for Action (HFA) 2005-2015 (UNISDR 2005). Creating a culture of earthquake safety should start with children and schools. Schools play an important role in the community. Schools may become a nucleus from where integrated safety is radiated to the rest of the territory and therefore, safe school helps in building community resilience (Wilches-Chaux 2007).

\section{Data analysis and damage scenario of school building during 2015 Gorkha Earthquake in Nepal}

According to Department of Education (DoE), Ministry of Education (MoE), Government of Nepal (GoN), 2015 Gorkha earthquake affected school buildings in 53 out of 75 districts in Nepal. Examples of damage of school buildings are shown in Fig. 2. The damages and losses in 53 districts are shown in Fig. 3, Fig. 4, and Fig. 5 respectively. Results show that about 9,345 (44\%) out of 21,017 schools have been affected by the earthquake (Fig. 3) and Fig. 5 shows the number of schools affected in district level. Similarly, about 22,371 (10\%) classrooms have been collapsed, about 13,818 (6\%) classrooms have been major-damaged, i.e. cracks on wall, significant cracks on doors and windows, out of plum of building, cracks on pillars/beams, significant cracks on infill walls, and about $18,436(8 \%)$ classrooms have been minor-damaged, i.e. minor hair cracks on building corners and door and windows, minor cracks on infill wall and no damage on beam and pillars in case of frame structure building, in the 53 districts (Fig. 4). Moreover, 14 districts (i.e., Kavrepalanchowk, Sindupalchowk, Dolakha, Kathmandu, Bhaktapur, Lalitpur, Ramechhap, Nuwakot, Dhading, Rasuwa, Gorkha, Makwanpur, Sindhuli, and Okhaldhunga) are considered as the most-affected districts and prioritized as emergency response for implementation of recovery and reconstruction program.

A committee has been formed in the Department of Education for overall management, data collecting, compiling and disseminating the data to the concern agencies.14 under-secretaries of the Department of Education are assigned as a focal persons for the data collection from the 14 most-affected districts and to support to the committee for compiling the data in the department. Survey was done using standard format developed after wider consultation with the different stakeholders, such as Department of Education (DoE), Department of Urban Development and Building Construction (DUDBC), The United Nations Children's Fund (UNICEF), Save the Children (SC), and others (Fig. 6) with the support of engineers, sub-engineers, resource-persons, school-supervisors and school-teachers. The Educational Management Information System (EMIS) code of each schools were taken from Flash Report 2015 of Department of Education and used as an identification number for analyzing the data (DOE 2015). School buildings were classified based on the construction materials used during construction, such as reinforce cement concrete (RCC), steel frame, adobe, bamboo, stone masonry with mud mortar, stone masonry with cement sand mortar, brick masonry with mud mortar, brick masonry with cement sand mortar, and others.

According to annual Flash Report 2015 of Department of Education, there are 5,748 schools, 112,045 students, 15,353 buildings, and 60,798 classrooms within the most-affected 14 districts of Nepal. The data analysis shows that approximately 4997 (86\%) schools have been affected by the earthquake in 14 
districts as shown in Fig. 7 and about one million students have been or still are out of schools for a longer period of time as a result of this. Figure 8 shows a distribution of the affected schools in 14 mostaffected districts by the 2015 Gorkha earthquake. The classrooms damage scenario in the 14 districts is shown in the Fig. 9 and Fig. 10 respectively. Result of the analysis shows that about 18,147 (30\%) classrooms have been collapsed (fully-damaged), about 8,020 (13\%) classrooms have been majordamaged, (Fig. 9). Similarly, about 10,380 classrooms (17\%) have been minor-damaged, and about 24,251 (40\%) classrooms have been found no damage (Fig. 9). However, the scenario of collapse and damage of school buildings in the districts (i.e., Gorkha, Sindupalchowk and Dolakha) located within or nearby the epicenter are quite different. Analysis and results show that about 1411 (97\%) out of 1448 schools have been affected by the earthquake in those three districts. Similarly, it was found that about 7838 (54\%) classrooms were collapsed (fully-damaged), about 2463 (17\%) classrooms were majordamaged, about 1887 (13\%) classrooms have been minor-damaged, and about 2334 (16\%) classrooms have been no-damage in those three districts. This shows that majority of buildings have been significantly damaged and suggests the high vulnerability of school buildings in those locations.

The data analysis in the 14 most-affected districts demonstrate that there are approximately $63 \%$ classrooms built with load-bearing masonry, about $21 \%$ built with reinforce-cement-concrete (RCC) framed structure, about $13 \%$ built with steel-frame structure, and about $4 \%$ with other materials, such as timber, thatch, etc. (Fig. 11 and Fig. 12). Analysis of the materials used for the construction of walls of the buildings show that there are approximately $49 \%$ classrooms walls built with stone in mud, about $31 \%$ built with brick in cement, about $8 \%$ built with stone in cement, about $4 \%$ built with brick in mud, about $1 \%$ built with bamboo, and only $0.2 \%$ walls with adobe (Fig. 13). This shows that the majority of schools building are load-bearing masonry buildings (Fig. 11 and Fig. 12) and majority of the walls are built with stone with mud mortar (Fig. 13); they are highly vulnerable to earthquake. Stone and brick masonry in mud mortar type buildings were damaged very heavily, whereas the brick masonry with cement sand mortar, reinforce cement concrete (RCC), and steel frame buildings were damaged partially. The major structural problem associated with the collapse of buildings is poor quality of construction materials, the de-lamination of the wall, lack of diaphragm, re-entrant corner, wall-junction failures, lack of seismic bands, mix-construction (e.g., ground floor stone masonry and upper floor brick masonry), lack of integrity between different structural members/elements, failure in beam column joint, and so on.

\section{Proposed plan for reconstruction of school buildings after 2015 Gorkha earthquake in Nepal}

The expansion of the school education sector has been rapid in Nepal. Before 1950, there were only 200 schools whereas in recent year; the number has reached 34,806 at the beginning of 2015 (DOE 16). Before 1970, almost all the school buildings had been constructed and maintained by the communities themselves without any financial aid and technical support from the government. There is still a lack of compressive policy to control the planning, design and construction of school buildings in Nepal. Recently, in order to promote access and increase quality of education, Government of Nepal has launched a number of initiatives with external and internal support, such as Education for All Program (2004-09), School Sector Reform Program (2009-15), and so no. Since no technical guidelines and plans 
have been provided, almost every school buildings are unique and patterned on the domestic buildings of its locality. Although some schools are supported by development partners and non-governmental organizations, many schools are directly constructed by the communities without incorporating any standard design criteria, guidelines and technical supervision. Presently, management of the public schools is largely the responsibility of the local community: government provides minimum financial support to run the schools (DOE 2016). The rest has to be managed by the community. Usually very low annual budget is available with the school management system. Such condition increases the likelihood that poor materials or workmanship are used in the construction of the school buildings making them structurally vulnerable to earthquake.

Most of the school buildings are not well maintained and they are locally constructed without any technical input. Most of those buildings are constructed using traditional materials (such as adobe, stone rubble in mud mortar or brick in mud mortar) that behave very poorly during earthquakes. Many school buildings are not only poorly constructed, but they also lack proper maintenance. Some of the buildings are in extremely poor condition due to sub-standard material or workmanship, lack of maintenance, or extreme age. Likewise, site specific hazard and risk analysis are also not considered during the design and construction. Some designs are available, but they are not entirely suitable for specific location. Therefore, development of appropriate policy, strategy and plan is necessary for the seismic improvement of school buildings after 2015 Gorkha earthquake in Nepal.

New construction and retrofitting/maintenance of large number of school buildings with the approach of Build Back Better (UNISDR 2015) within the limited period of time is almost impossible. However, there is an urgent need of reconstruction and retrofit of existing earthquake damaged (i.e., vulnerable) school buildings in order to save the large number of school-going children and the properties from the expected future earthquake disaster in Nepal. There are two options available for seismic improvement of school buildings: i) demolishing the existing vulnerable buildings and debris management of the demolished and damaged buildings and then replaced by new buildings; and ii) retrofitting/seismic-strengthening of the partial damage/vulnerable buildings. Based on the first option, demolishing the existing vulnerable buildings and reconstructing seems easy and attractive from a technical point of view but it is uneconomical (Dixit et al. 2014; Paudyal and Vishokarma 2013). It is not only the cost but also the magnitude and duration of disturbance to the existing school functions. This will be very high in the first option (more than 1 year in comparison to 2-3 months in second one) (Dixit et al. 2014; Paudyal and Vishokarma 2013). The second option seems economical, attractive and new because this technology provides good opportunity to learn more to the community, school management committee, teachers and students (Cardona 2007; Paudyal and Vishokarma 2013). Implementation of school reconstruction/retrofitting program would also provide an opportunity for social dialogue, increased awareness, preparedness planning, and masons' training thereby the opportunity for replication and hence inculcating a culture of safety in the community as well (Sharma and Gupta 2007).

Construction of large number of school buildings at a time is a challenging mission for the government. It needs enough financial resources, large number of contractors, adequate technical manpower to 
supervise the construction activities, adequate quality control mechanism, such as material testing laboratory, and enough construction materials which is almost an impossible for the developing country like Nepal. It is hardly possible for the Government of Nepal to allocate immense financial resources only for the purpose of new construction and retrofitting of school buildings. However, reconstruction of school buildings and retrofit of existing vulnerable buildings (i.e., damage, partial-damage) after 2015 Gorkha earthquake is an urgent need to provide an appropriate teaching learning environment in the schools as soon as possible. This is also an urgent requirement to protect life of large number of young people and to save huge economic losses in the country from the expected future earthquake disaster in Nepal.

Looking towards the present scenario of collapsed and damaged school buildings, it is necessary to implement the school reconstruction program with minimum cost without compromising the structural safety of the schools. For this, timely formulation of an appropriate reconstruction strategy and plan and implementation of it is an important step. Figure 14 shows the proposed plan/strategy for effective implementation of the school reconstruction program after 2015 Gorkha earthquake in Nepal. The details of each sub-component of the proposed strategy are described in the following sections.

\section{Rapid Visual Vulnerability Assessment Of School Buildings}

Rapid visual vulnerability assessment of school buildings is done for screening the collapse, vulnerable and non-vulnerable school buildings. This method can be used rapidly and easily to identify those buildings that might pose a risk of life or injury. This assessment procedure will provide more reliable assessment for the seismic vulnerability of the buildings, and will form the basis for determining need for more complex seismic vulnerability assessment (Paudyal et al. 2009). This method is used to short-list the buildings to which simplified vulnerability assessment procedure should be applied. The rapid visual screening method is designed to be implemented without performing any structural calculations. The main applications of this procedure are to identify if a particular building requires further evaluation for assessment of its seismic vulnerability and to rank school seismic strengthening needs. In this step, we categorize the school buildings into following three types which is based on the damage grade mentioned in the European Macroseismic Scale 1998 (EMS-98) (Table 1).

- Minor damage buildings (less vulnerable) - Grade 1 (G1) type

- Damage buildings (vulnerable) - Grade 2 (G2), Grade 3 (G3) and Grade 4 (G4) type

- Collapse buildings - Grade 5 (G5) type

From rapid visual vulnerability assessment, we shortlist the school buildings from the list which have collapsed and in the same time, we can make a program for debris management and then reconstruction plan for new buildings. For transitional arrangement for running the classes in the schools, these schools will be supported by temporary/semi-permanent classrooms based on the requirements. Similarly, we categorize the list of less-vulnerable buildings which are G1 type based on the EMS-98. These buildings require only minor repair and maintenance and can be addressed by using maintenance guidelines with 
minimum financial support from the government and community. Damage buildings which are vulnerable to use (i.e., G2, G4 and G5 type as per the EMS-98) and difficult to ascertain their characteristic need further investigation. Those schools which have the partial-damage/vulnerable buildings will be supported by the temporary/semi-permanent classrooms as a transitional arrangement to run the classes until vulnerable buildings will be retrofitted. Therefore, rapid visual vulnerability assessment of buildings is an important activity that need to be performed carefully for screening the buildings. Further detail damage assessment is needed for the damage buildings (i.e., G2, G3 and G4 type as per ems-98) to ascertain the type of intervention needed to strengthening the buildings. Therefore, from this screening method, we can easily prepare the list of school buildings which need, namely, i) reconstruction program; ii) maintenance program, iii) detail vulnerability assessment program.

\section{Detail vulnerability assessment of school buildings}

Detail vulnerability assessment of school buildings is done for damage and vulnerable school buildings (i.e., G2, G3 and G4 type as per EMS-98) which are identified from rapid visual vulnerability assessment. This method utilizes engineering information such as size and strength of lateral load resisting members and more explicit information on the design ground motion. This data is used to carry out a highly simplified analysis of the structure to estimate the building drift. Since good correlation exists between building drift and damage, the analysis results can be used to estimate the potential seismic risk of the building. From this analysis method, we can identify appropriate retrofitting methods to be used for strengthening of structural member. So, from this detail assessment, we can develop a detail program and implementation modality for retrofitting of school buildings. This will again help in reducing the cost of preventative measure used without compromising structural safety of the building.

From detailed vulnerability assessment, we can identify the most critical school buildings which need retrofitting/strengthening program. We can categorize the school buildings in the following three ways based on the urgency of retrofitting program in schools.

- Buildings required minor-retrofitting/retro-maintenance program

- Buildings required retrofitting program

- Buildings required demolished, debris management and new construction program

Based on the available budget and manpower, we can implement the program phase-wise. First priority should be given to those buildings which require immediate retrofitting program. If earthquake occurs, these buildings might be damaged heavenly and hence there may be huge properties loss and threating to the life of the students as well. So, we should implement retrofitting program for such vulnerable buildings first. Similarly, retro-maintenance for the minor-damage buildings will be done simultaneously using maintenance/retro-maintenance guideline.

The main objective of the detail vulnerability assessment of buildings is to evaluate the buildings capacity to resist the earthquake demand and identify the appropriate retrofitting technique to make it safe from the future earthquake demand. However, there might be some buildings which may need to 
demolish rather going for retrofit because of uneconomical for retrofitting and other requirements of the schools, such as insufficient space, horizontal and vertical expansion of rooms, and other social and cultural requirements. For those buildings, it is better to demolish the existing vulnerable buildings and prepare the program for debris management and new construction accordingly.

\section{Reconstruction and retrofitting of school buildings}

As described above, reconstruction of the school buildings after 2015 Gorkha earthquake is one of the priority areas for the Government of Nepal. Short term plan will be made for the maintenance or retromaintenance of school buildings. This can be done with small support from the government through community using retro-maintenance guideline or maintenance guideline. However, retrofitting and reconstruction of school building will take longer-period and require immense financial resources and therefore need to make medium-term or long-term program (Figure 14).

There are two ways for reconstruction and retrofitting of school buildings

- Construction through contractor

- Construction through community

Construction of school buildings using contractor could be the preferred option instead of construction through community from technical point of view. School buildings are not only a place for teaching and learning but also the place for the emergency shelter during and after disaster. They should be resilient from the disasters. Retrofitting and reconstruction of complex buildings and big buildings needs sound technical knowledge to implement and therefore, only qualified contractor can only do such works. It also needs intensive technical supervision from technical persons. However, the construction and retrofitting of small size and simple types of school buildings (i.e., 1 to 2 story) which may need less technical input, can be done through community using proto-type design. However, construction through community requires intensive technical supervision from technical manpower to make the constructed facilities resilient to disaster. Separate provision for material quality testing and provision for construction quality checking mechanism is pre-equisetic to maintain and assure the specification of the constructed facilities. Strong school construction management mechanism is also needed to run the construction project smoothly without any delay and problem within the member of the community.

Community involvement plays an important role to reduce the cost of preventative measure. People can participate in the program and contribute themselves by providing grant or manpower. For developing country like Nepal, community participation is one of the major factors for reducing the cost of the project as well. Community participation helps not only to reduce the cost of the project but also make the project sustainable. They are informed about the amount of budget received from the different sources and amount of budget spent in a project and therefore improve the transparency in the community. They feel the projects like their own and maintain the constructed facilities properly in the long run. 
Disaster prevention is a cultural issue (Sharma and Gupta, 2007). Various programs and international campaign have been lunched for building a culture of prevention. However, there is still many things need to be done to build this culture in those parts of the world which are most vulnerable and most prone to recurrent disasters. The basic objective of any disaster prevention program is to decrease the loss of life, property destruction and social and economic disruption caused by natural disasters, such as earthquakes, landslides etc. The other important objective is to build safer communities. This includes community participation in disaster prevention works, training to local masons and technicians about disaster prevention works, and training to students, teachers and community about disasters (Paci-Green et al. 2015).

Community involvement plays a very important role for making them aware about the disaster and its prevention. This is an ongoing challenge for every nation to improve communities understanding of the risk they face and empower them to take action to reduce these risks and to manage consequences of disaster. Community engagement during construction is very important. It builds trust of the locals in the reconstruction projects. Without their engagement, it will be sometimes misunderstood during project implementation. Paci-Green et al. 2015 has conducted the survey of the schools after 2015 Gorkha earthquake in Nepal. According to Paci-Green et al. 2015, the community engagement projects showed better knowledge of risk of disasters and earthquake-resistant construction technology in people, and they became the advocates for safer construction after 2015 Gorkha earthquake in Nepal as well. Therefore, community engagement and awareness building is very important during reconstruction of school building. Community engagement is not only help to reduce the cost of the project but also help to make it sustainable and it also creates awareness about disaster, its impact and preventative measures.

\section{Concluding Remarks}

This study is one of the first attempt to address the issue of earthquake disaster risk mitigation of school buildings after the 2015 Gorkha earthquake in Nepal. The 2015 Gorkha earthquake has devastated about 9,000 schools in Nepal. Damage distribution in the most-affected 14 districts shows that previous construction practices were an important determent for the intensity of the damage observed across these districts. The use of improper construction materials, lack of construction supervision, and noncompliance with existing building codes during design and construction contributed to most of the school buildings to be severely or fully damaged. In addition to the physical damage to infrastructure, there is a significant psychological impact in terms of the effect that the disaster had on the mental health of on the school-going children, their parents and teachers within the affected areas. Preliminary damage assessment results show that in the most affected districts, about $86 \%$ schools have been affected by the earthquakes and about one million students have been or still are out of schools for a longer period of time as a result of this. Preliminary data shows that about $30 \%$ classrooms are collapsed, about $13 \%$ classrooms are major-damaged, and about $17 \%$ are minor-damaged with in the most affected 14 districts. 
Construction of large number of school buildings at a time is a challenging mission for the government. It needs immense financial resources, large number of contractors, adequate technical manpower to supervise the construction activities, efficient quality control mechanism, such as material testing laboratory, and enough construction materials which is almost an impossible for the developing country like Nepal. It is hardly possible for the Government of Nepal to allocate adequate financial resources only for the purpose of new construction and retrofitting of school buildings. However, reconstruction of school buildings and retrofitting of existing vulnerable buildings (i.e., damage, partial-damage) after 2015 Gorkha earthquake is an urgent need to provide an appropriate teaching learning environment in the schools as soon as possible. This is also an urgent requirement to protect the life of large number of young people and to save huge economic losses in the country from the expected future earthquake disaster in Nepal. Therefore, this paper attempts to identify the needs to be addressed for the reconstruction school buildings after 2015 Gorkha earthquake in Nepal.

Firstly, rapid visual seismic vulnerability assessment of school buildings needs to be done to identify those buildings that might pose a risk of life and injury. From the rapid visual vulnerability assessment, we can categorize the buildings in different groups, such as collapse/fully-damage buildings; the partialdamage/vulnerable buildings required seismic strengthening; and less-vulnerable buildings required simple repair and maintenance program only.

Secondly, detail vulnerability assessment can be done for the partial-damage/vulnerable buildings so that they can be categorized as per the type of retrofitting techniques necessary and amount of financial resources required for implementing the retrofitting program. This helps for launching program in priority order as per the urgency of retrofitting works in schools.

Thirdly, reconstruction and retrofitting program should be designed in such a way that it has to be enhanced community participation during all the phases of the program implementation, i.e. from planning to reconstruction and maintenance of school buildings. Community engagement in a construction program will improve better knowledge of risk of disasters and earthquake-resistant construction technology to them and they became the advocates for safer construction after expected future disaster in Nepal. Community participation not only helps to reduce the cost of the project but also helps to make it sustainable and it also creates awareness about disaster, its impact and preventative measures.

\section{Declarations}

\section{Availability of data and material}

All the data and materials used are mentioned in the manuscript.

\section{Competing interests}

The author's declare that they have no competing interest. 


\section{Funding}

Japan Student Services Organization (JASSO) fellowship program (November 1, 2016 to January 29, 2017) from the Government of Japan.

\section{Authors' contributions}

YRP compile data and performed the analysis. He also drafted the manuscript. NPB and RY give suggestions on methodology and conclusions. All three authors read and approved the final manuscript.

\section{Acknowledgements}

The research has been conducted with the help from officials of Department of Education. Mr. Jhapper Singh Vishwakarma, DOE and Mr. Jimi Oostrum, UNICEF are also acknowledged for their support and suggestion during preparation of the manuscript.

Finally, the financial support received from the Government of Japan in the name of Japan Student Services Organization (JASSO) fellowship program (Research Advisor: Prof. Ryuichi Yatabe, Ehime University) is sincerely acknowledged.

\section{References}

Ando S, Pandey BH, Fujieda A. 2007. Making schools safe from earthquakes through retrofitting, training, and disaster education: A case study of the UNCRD SESI Project. Regional development dialogue. United Nationals Centre for Regional Development, Nagoya, Japan 28(2), p. 148

Bilham R, Bodin P, Jackson M. 1995. Entertaining a Great Earthquake in western Nepal: historic inactivity and geodetic tests for the present state of strain. Journal of Nepal Geological Society. 11(1):73-78.

Dixit AM, Yatabe R, Dahal RK, Bhandary NP. 2014. Public School Earthquake Safety Program in Nepal, Geomatics. Natural Hazards and Risk. 5(4):293-319. DOI: 10.1080/19475705.2013.806363

DoE. 2015. Flash Report 2015-16. Department of Education, Ministry of Education, Government of Nepal.

DUDBC. 2016. Department of Urban Development and Building Construction, Ministry of Urban Development, Governent of Nepal.

Finnis K, Johnston D, Becker J, Ronan KR, Paton D. 2007. School and community-based hazards education and links to disaster-resilient communities. Regional development dialogue. United Nationals Centre for Regional Development, Nagoya, Japan 28(2), p. 148

Nathe SK. 2000. Public education for earthquake hazards. Natural Hazards Review, November; p. 191196. doi: dx.doi.org/10.1061/(ASCE)1527-6988(2000)1:4(191). 
Pandey MR, Tandukar RP, Avouac JP, Lavé J, Massot JP. 1995. Interseismic strain accumulation on the Himalayan crustal ramp (Nepal). Geophysical Research Letters. 22(7):751-754.

Paci-Green R, Pandey B, Friedman R. 1014. Safer Schools, Resilient Communities: A Comparative Assessment of School Safety after the 2015 Nepal (Gorkha) Earthquakes. Risk RED. P. 37. http://riskred.wix.com/riskrednepal

Pandey MR, Molnar P. 1988. The distribution of intensity of the Bihar-Nepal earthquake 15 January 1934 and bounds of the extent of the rupture zone. Journal of Nepal Geological Society. 5:22-44.

Parajuli R. 2020. Citizen Disaster Science Education for effective disaster risk reduction in developing countries. Geoenvironmental Disasters 7:12. doi.org/10.1186/s40677-020-00150-2

Paudyal YR, Subedi J, Shrestha R. 2009. Rapid Visual Seismic Vulnerability Assessment Tool for Kathmandu Valley. Technical Journal, Nepal Engineers' Association. 100-108

Paudyal Y, Bhandary N, Yatabe R. 2012a. Seismic microzonation of densely populated area of Kathmandu Valley of Nepal using microtremor observations. Journal of Earthquake Engineering. 16 (8):1208-1229.

Paudyal YR, Yatabe R, Bhandary N, Dahal RK. 2012b. A study of local amplification effect of soil layers on ground motion in the Kathmandu Valley using microtremor analysis. Earthquake Engineering and Engineering Vibration. 11(2):257-268.

Paudyal YR, Yatabe R, Bhandary NP, Dahal RK. 2013a. Basement topography of the Kathmandu Basin using microtremor observations. Journal of Asian Earth Sciences. 62:627-637.

Paudyal YR, Vishokarma JS. 2013b. Methodology for effective implementation of School Retrofitting Program in Nepal. Journal of Teacher Education, Nepal. 236-243

PDNA. 2015. Post Disaster Needs Assessment. National Planning Commission, Government of Nepal.

Petal M. 2007. Disaster risk reduction education material development, organization and evaluation. Regional development dialogue. United Nationals Centre for Regional Development, Nagoya, Japan 28(2), p. 148

Rana BJB (1935) Nepal Ko Maha Bhukampa (Great earthquake of Nepal). Jorganesh Press.

Sharma A, Gupta M. 2007. Building community resilience through education: school safety as a route to a culture of prevention. Regional development dialogue. United Nationals Centre for Regional Development, Nagoya, Japan 28(2), p. 148

Tuladhar G, Yatabe R, Dahal RK, Bhandary NP. 2014. Knowledge of disaster risk reduction among school students in Nepal. Geomatics, Natural Hazards and Risk. 5(3):190-207, DOI: 
Tuladhar G, Yatabe R, Dahal RK, Bhandary NP. 2015. Disaster risk reduction knowledge of local people in Nepal. Geoenvironmental Disaster. 2:5: DOI 10.1186/s40677-014-0011-4

UNISDR. 2004. Hyogo framework for action 2005-2015. United Nations Inter-Agency Secretariat of the International Strategy for Disaster Reduction; Geneva, Switzerland. [cited 2013 Jan 23]. Available from: http://www.unisdr.org/2005/wcdr/intergover/ official-doc/L-docs/ Hyogo-framework-for-actionenglish.pdf

UNISDR. 2007. Towards a culture of prevention: disaster risk reduction begins at school - good practices and lessons learned. United Nations International Strategy for Disaster Reduction; Geneva, Switzerland. p. 143.

UNISDR. 2011. Compilation of national progress reports on the implementation of the hyogo framework for action. HFA Priority 3, Core Indicator 3.2; Geneva, Switzerland. Available from:

http://www.preventionweb.net/english/hyogo/framework/progress/

UNISDR. 2015. The Sendai Framework for Disaster Risk Reduction 2015-2030.

http://www.unisdr.org/we/coordinate/sendai-framework

Wilches-Chaux G. 2007. Safe Schools in Safe Territory. Regional development dialogue. United Nationals Centre for Regional Development, Nagoya, Japan 28(2), p. 148

\section{Tables}


Table 1 Damage grade based on the European Macroseimic Scale 1998

\begin{tabular}{|c|c|c|c|c|}
\hline Damage & \multicolumn{2}{|c|}{ Load bearing masonry building } & \multicolumn{2}{|c|}{ Reinforce cement concrecte building } \\
\hline Grade 1 & $\begin{array}{l}\text { Negligible to slight damage } \\
\text { (no structural damage, } \\
\text { slight non-structural } \\
\text { damage) } \\
\text { - Hair-line cracks in very } \\
\text { few walls } \\
\text { - Fall of small pieces of } \\
\text { plaster only } \\
\text { - Fall of loose stones from } \\
\text { upper parts of buildings in } \\
\text { very few cases }\end{array}$ & 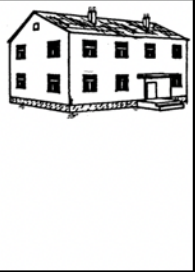 & $\begin{array}{l}\text { Negligible to slight } \\
\text { damage (no structural } \\
\text { damage, slight non- } \\
\text { structural damage) } \\
\text { - Hair-line cracks in plaster } \\
\text { over frame members or in } \\
\text { walls at the base, } \\
\text { - Fine cracks in partitions } \\
\text { and infills }\end{array}$ & 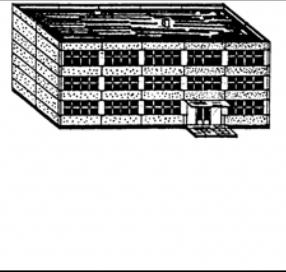 \\
\hline Grade 2 & $\begin{array}{l}\text { Moderate damage (slight } \\
\text { structural damage, } \\
\text { moderate non-structural } \\
\text { damage) } \\
\text { - Cracks in many walls } \\
\text { - Fall of fairly large pieces of } \\
\text { plaster } \\
\text { - Partial collapse of } \\
\text { chimneys }\end{array}$ & 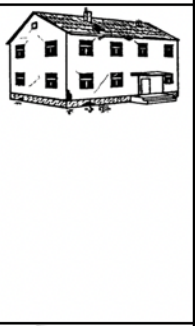 & $\begin{array}{l}\text { - Moderate damage (slight } \\
\text { structural damage, } \\
\text { moderate non-structural } \\
\text { damage) } \\
\text { - Cracks in columns and } \\
\text { beams of frames and in } \\
\text { structural walls } \\
\text { - Cracks in partition and } \\
\text { infill walls } \\
\text { - Fall of brittle cladding and } \\
\text { plaster } \\
\text { - Falling mortar from the } \\
\text { joints of wall panels }\end{array}$ & 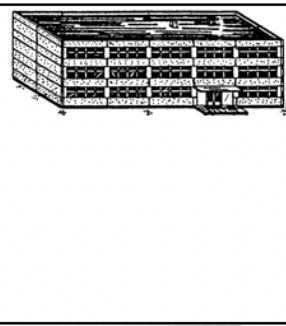 \\
\hline Grade 3 & $\begin{array}{l}\text { - Substantial to heavy } \\
\text { damage (moderate } \\
\text { structural damage, heavy } \\
\text { non-structural damage) } \\
\text { - Large and extensive cracks } \\
\text { in most walls } \\
\text { - Roof tiles detach Chimneys } \\
\text { fracture at the roof line; } \\
\text { failure of individual non- } \\
\text { structural elements } \\
\text { (partitions, gable walls) }\end{array}$ & 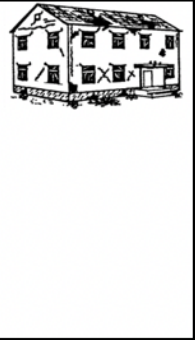 & $\begin{array}{l}\text { - Substantial to heavy } \\
\text { damage (moderate } \\
\text { structural damage, heavy } \\
\text { non-structural damage) } \\
\text { - Cracks in columns and } \\
\text { beam column joints of } \\
\text { frames at the base and at } \\
\text { joints of coupled walls. } \\
\text { Spilling of concrete cover, } \\
\text { buckling of reinforced } \\
\text { rods } \\
\text { - Large cracks in partition } \\
\text { and infill walls, failure of } \\
\text { individual infill panels }\end{array}$ & mingen \\
\hline Grade 4 & $\begin{array}{l}\text { Very heavy damage (heavy } \\
\text { structural damage, very } \\
\text { heavy non-structural } \\
\text { damage) } \\
\text { - Serious failure of walls; } \\
\text { partial structural failure of } \\
\text { roofs and floors }\end{array}$ & 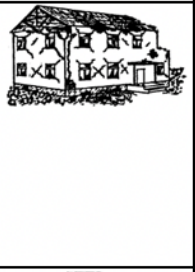 & $\begin{array}{l}\text { Very heavy damage } \\
\text { (heavy structural damage, } \\
\text { very heavy non-structural } \\
\text { damage) } \\
\text { - Large cracks in structural } \\
\text { elements with } \\
\text { compression failure of } \\
\text { concrete and fracture of } \\
\text { rears; tilting of columns. } \\
\text { Collapse of a few columns } \\
\text { or of a single upper floor }\end{array}$ & 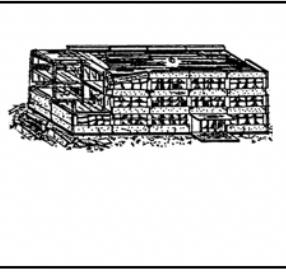 \\
\hline Grade 5 & $\begin{array}{l}\text { - Destruction (very heavy } \\
\text { structural damage) } \\
\text { - Total or near total collapse }\end{array}$ & 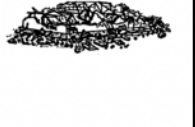 & $\begin{array}{l}\text { - Destruction (very heavy } \\
\text { structural damage) } \\
\text { - Collapse of ground floor } \\
\text { or parts (e. g. wings) of } \\
\text { buildings }\end{array}$ & 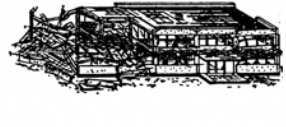 \\
\hline
\end{tabular}

\section{Figures}




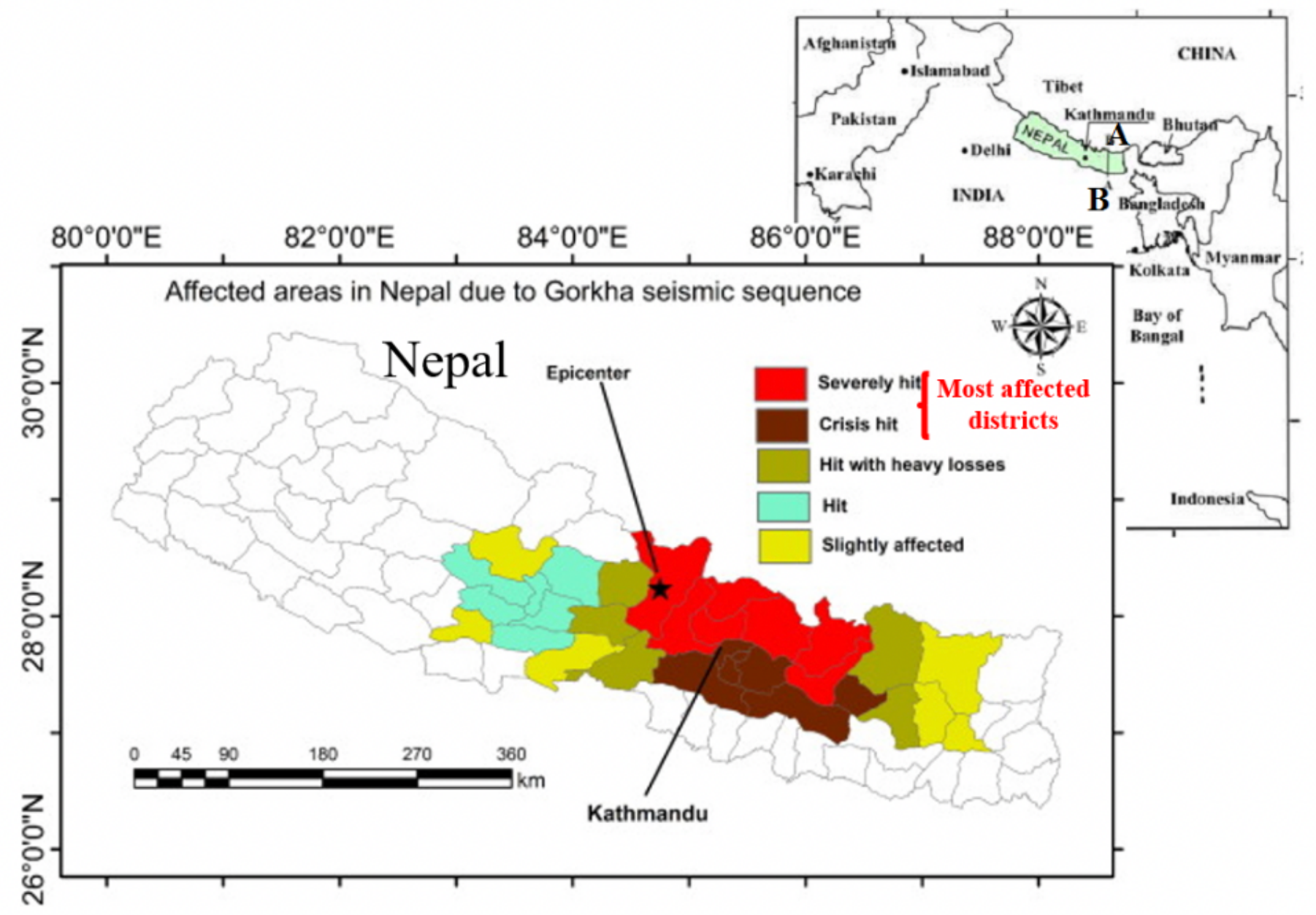

Figure 1

Location of Nepal and affected districts by the 2015 Gorkha earthquake in Nepal (the red and maroon colors show the most affected 14 districts) (PDNA 2015)

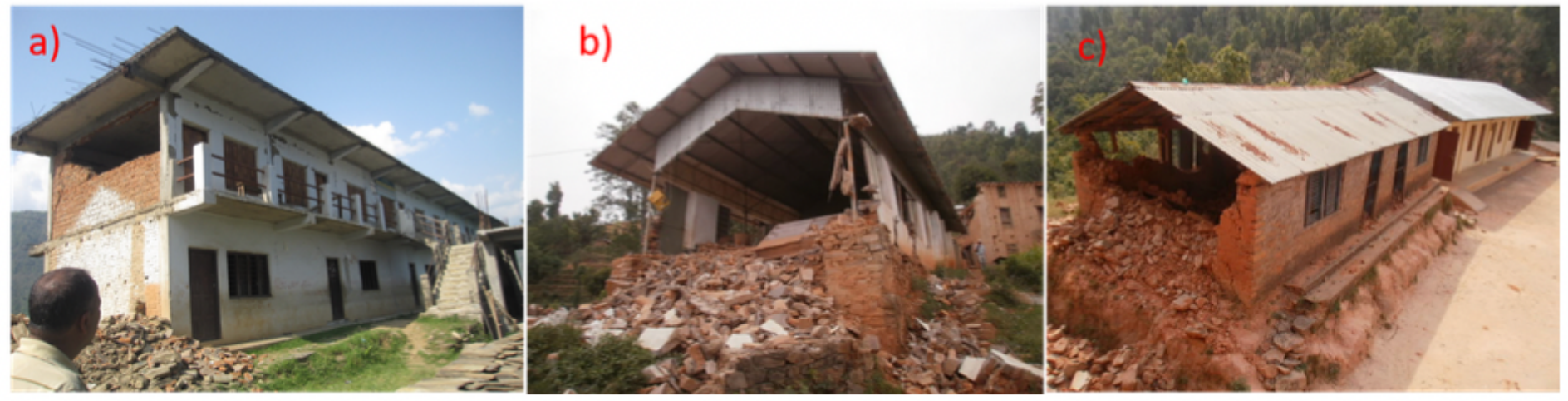

Figure 2

Typical example of damage of school buildings during 2015 Gorkha earthquake (a) reinforce cement concrete, b) steel frame with masonry walls, and c) stone masonry with mud mortar) 


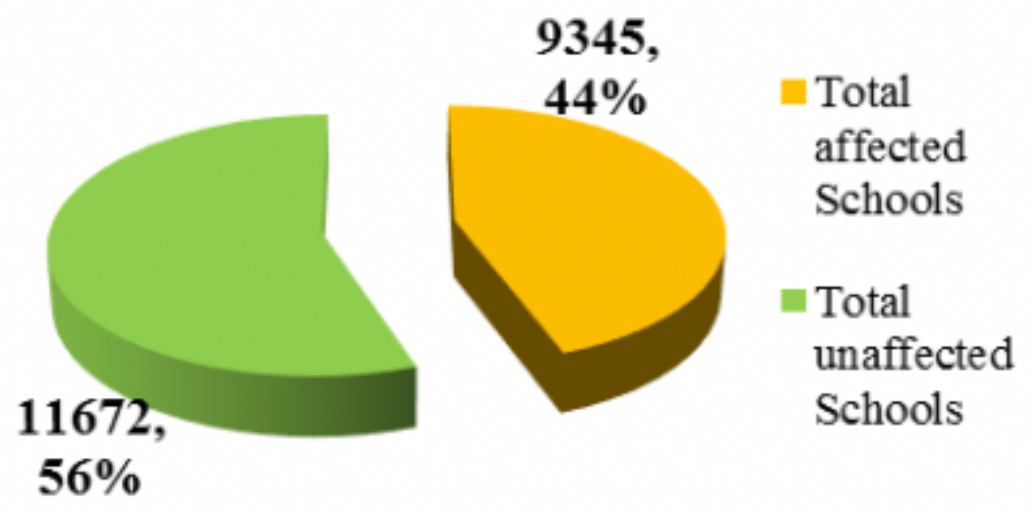

Figure 3

Affected and unaffected percentage of schools in 53 districts

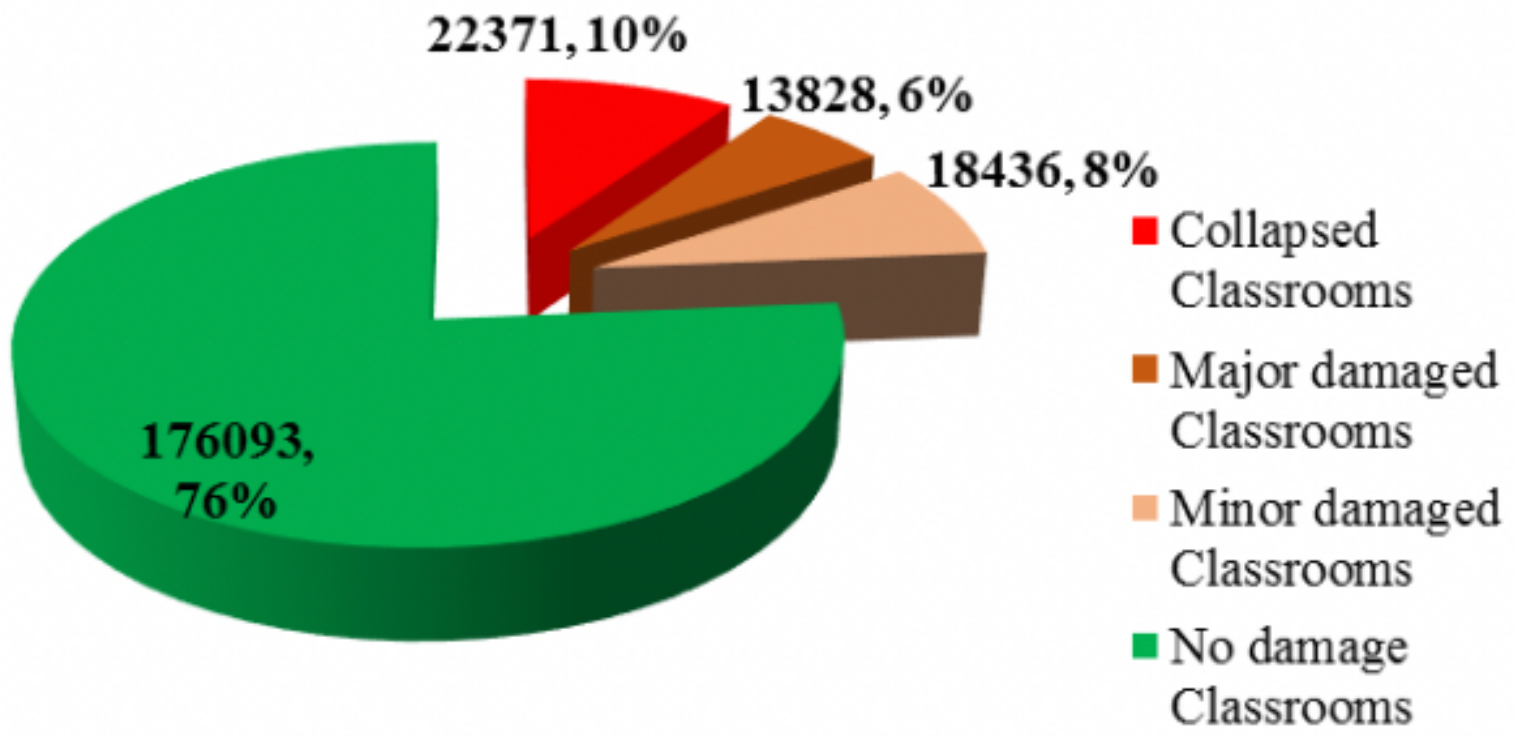

Figure 4

Damage Scenario of School Buildings in 53 districts of Nepal 


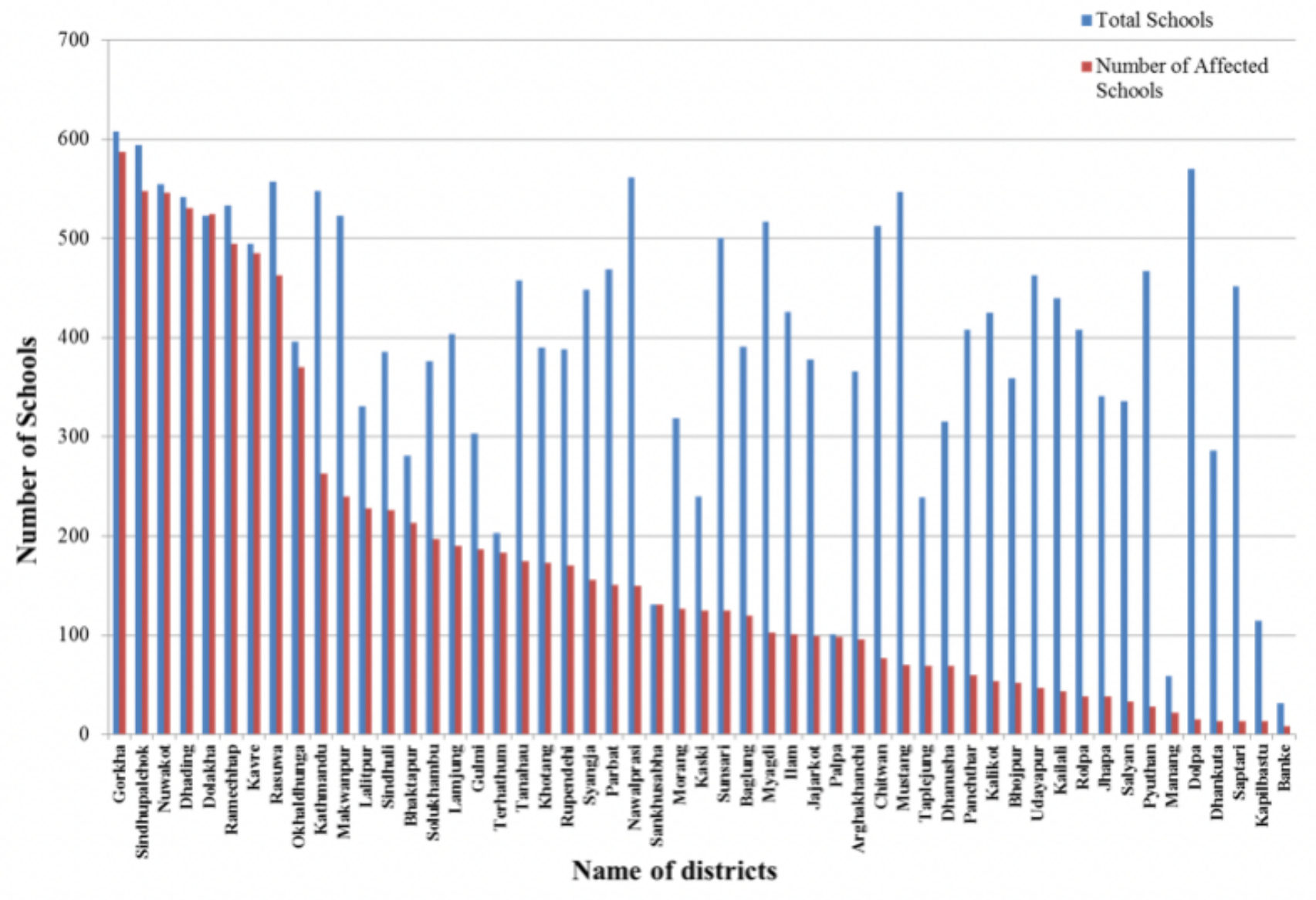

Figure 5

Total and affected schools in 53 districts 
Rapid Damage (Technical) Assessment of Schools:

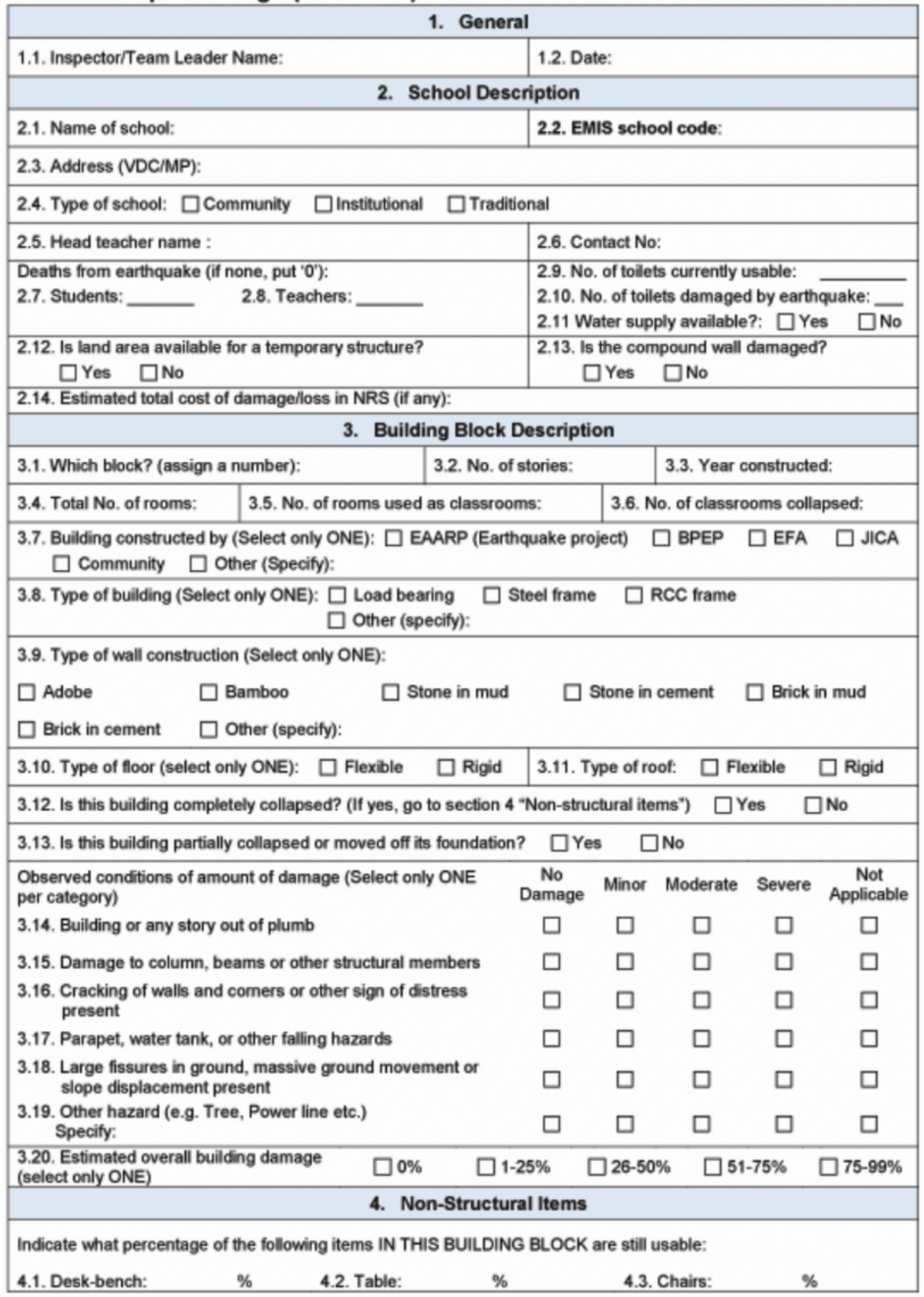

\section{Figure 6}

Rapid damage assessment form developed after 2015 Gorkha earthquake in Nepal 


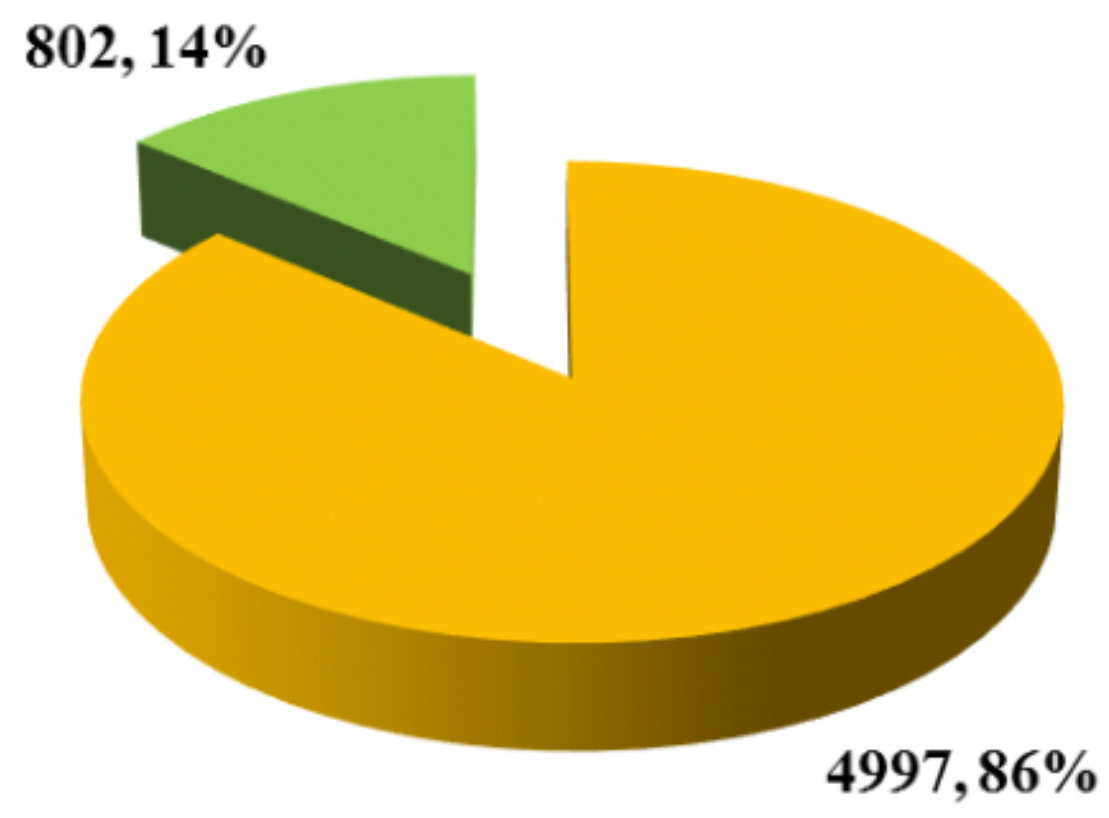

Total affected Schools

Total unaffected Schools

Figure 7

Affected percentage of schools in 14 districts

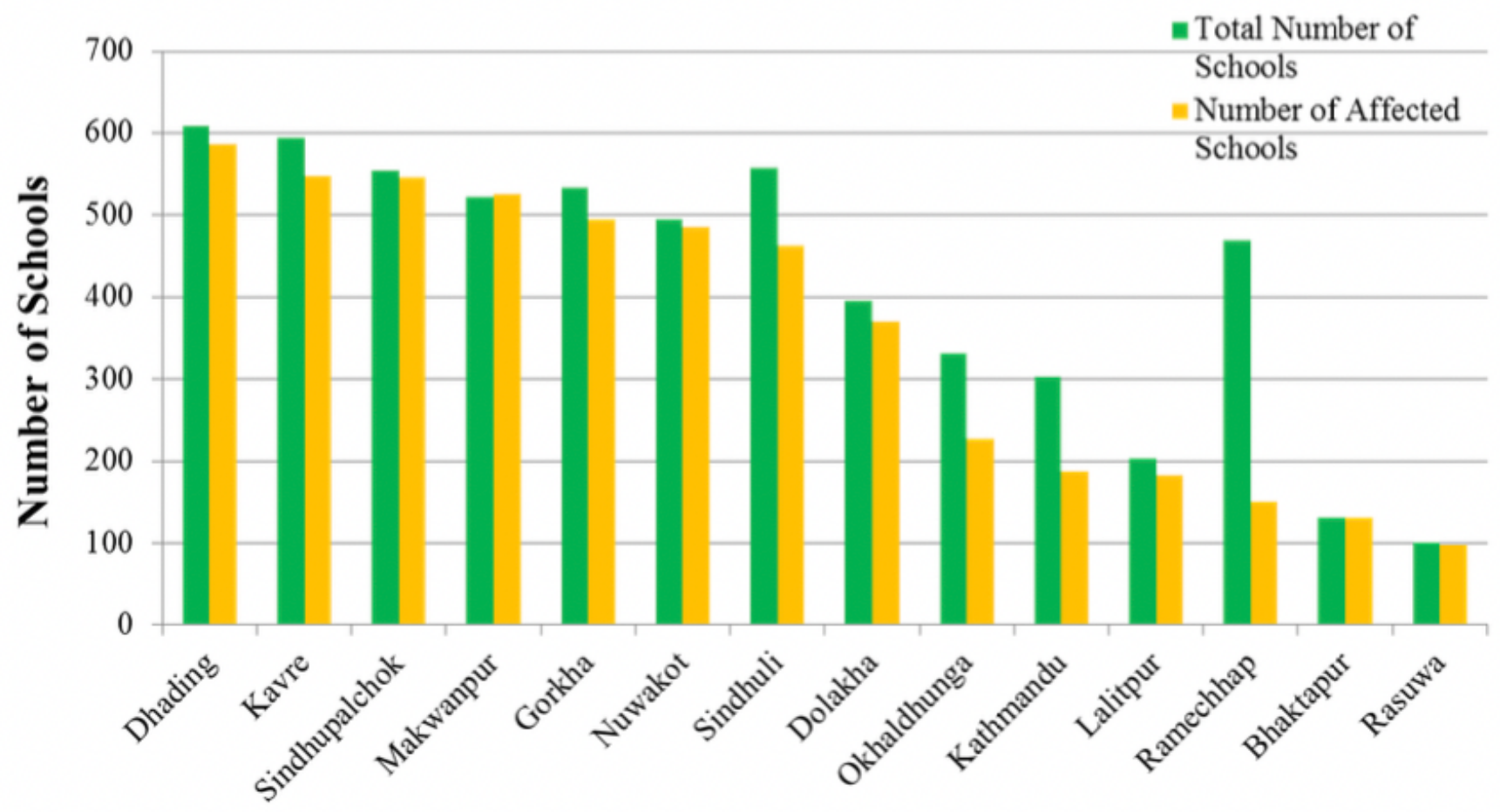

Name of districts 
Figure 8

Distribution of affected schools after 2015 Gorkha earthquake in 14 districts

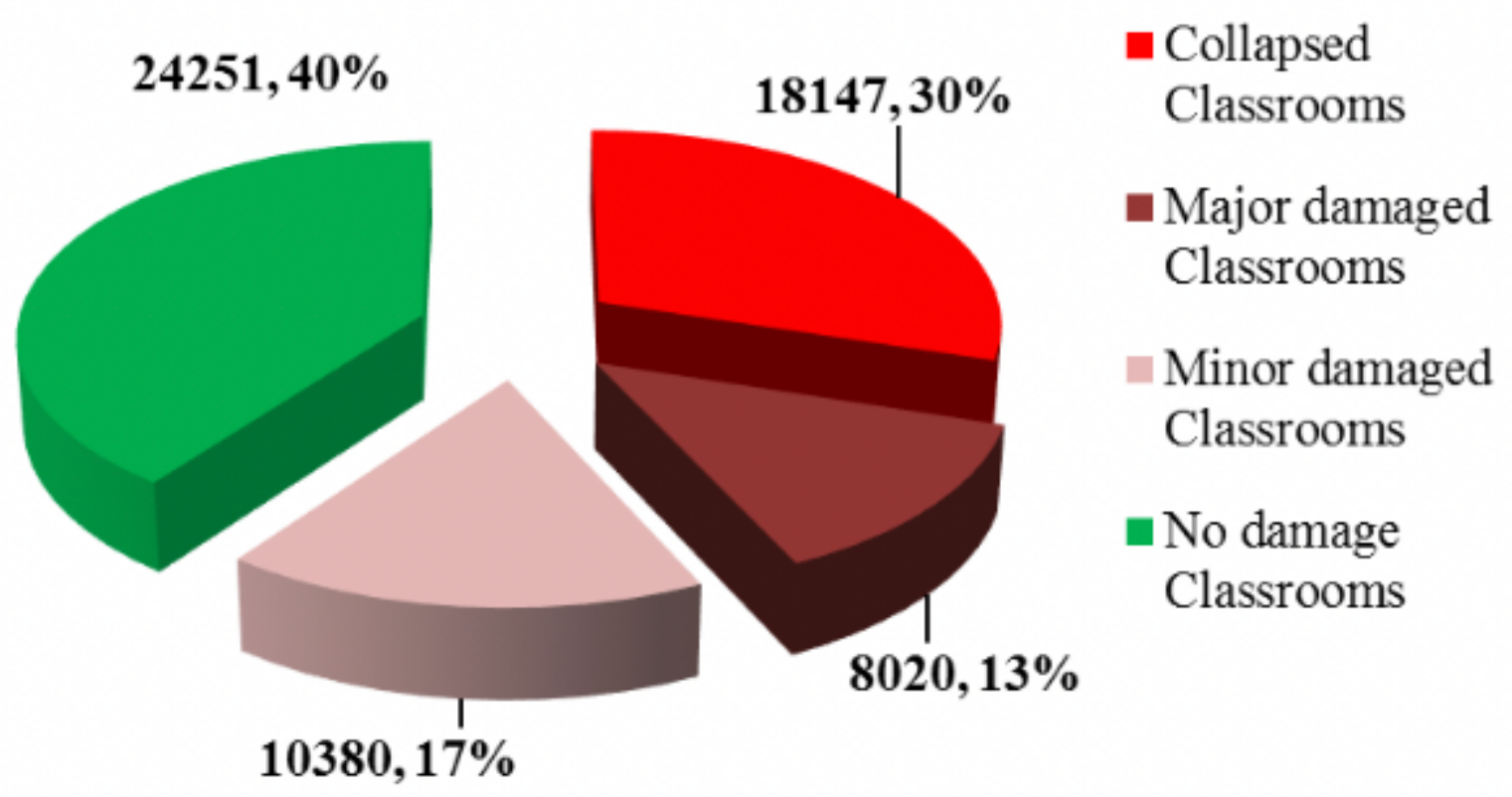

Figure 9

Percentage of classroom damage in 14 districts 


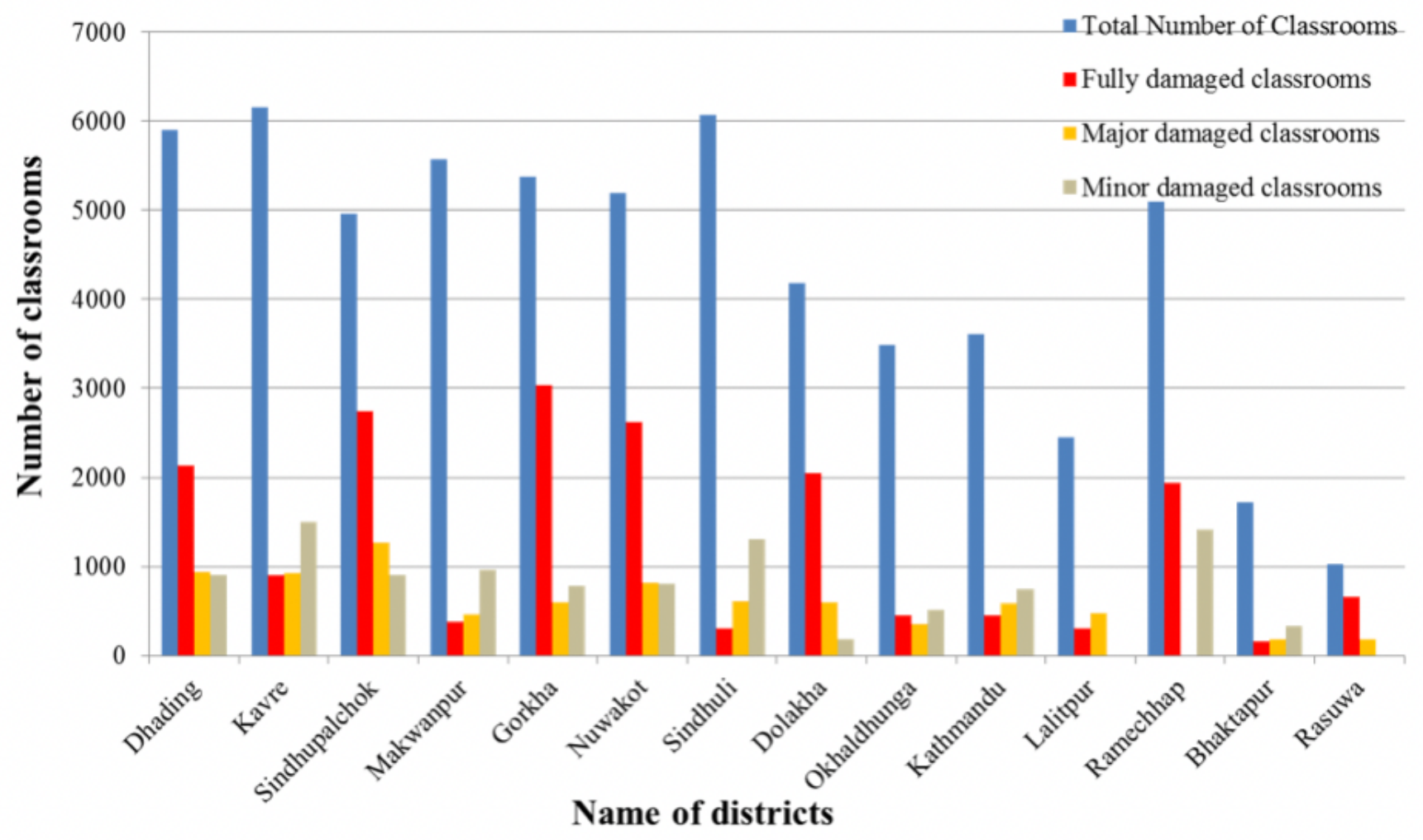

Figure 10

Scenario of classrooms damage in 14 districts

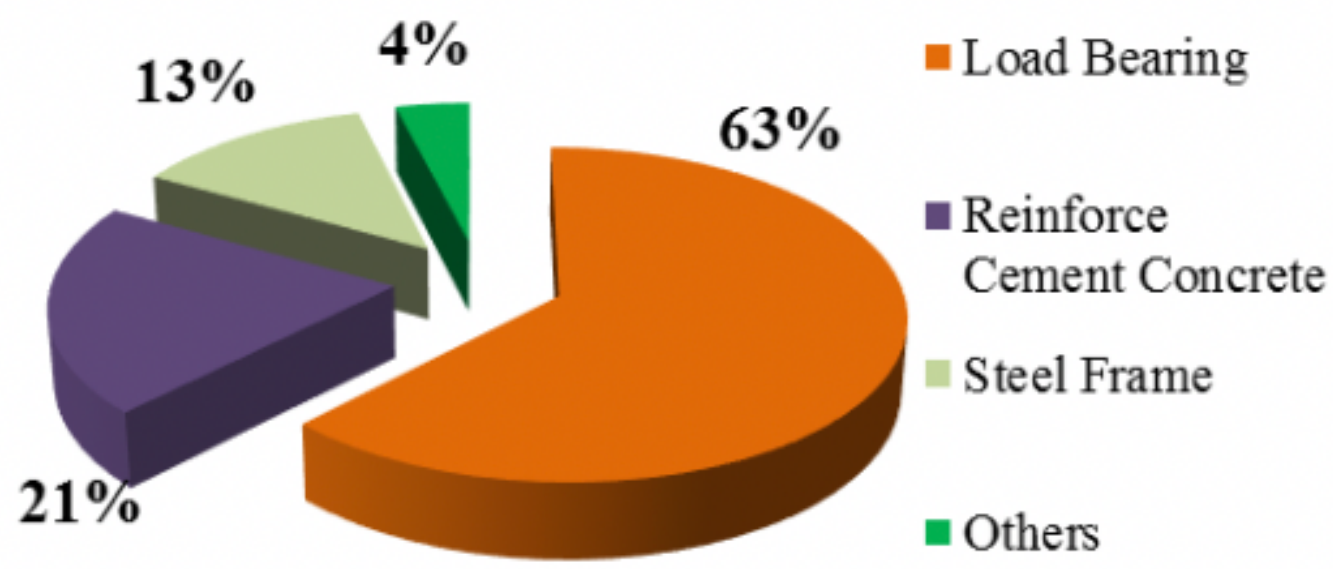

Figure 11

Type of buildings in 14 districts 


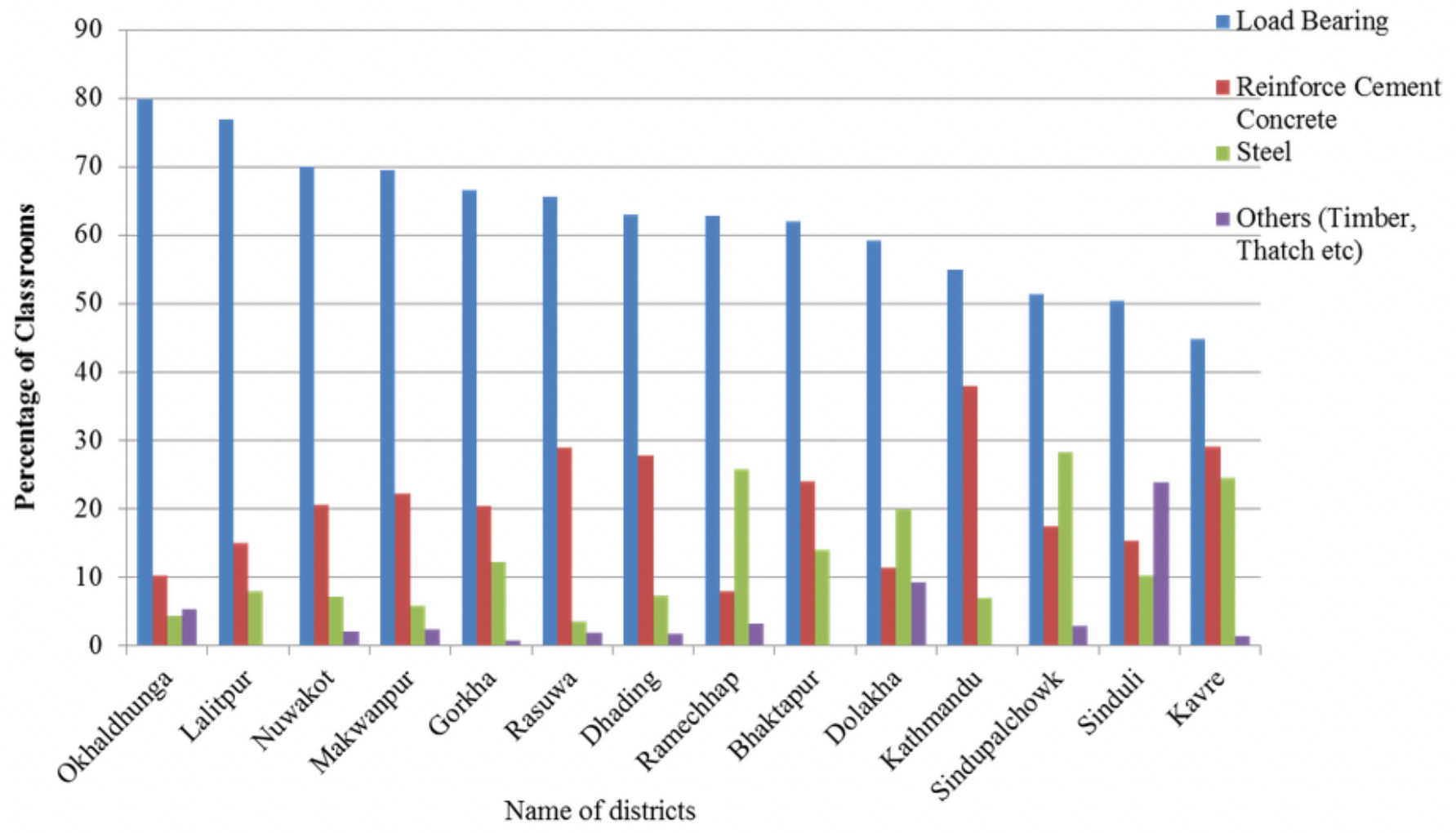

Figure 12

Type of classroom in terms of material used during construction in 14 districts 


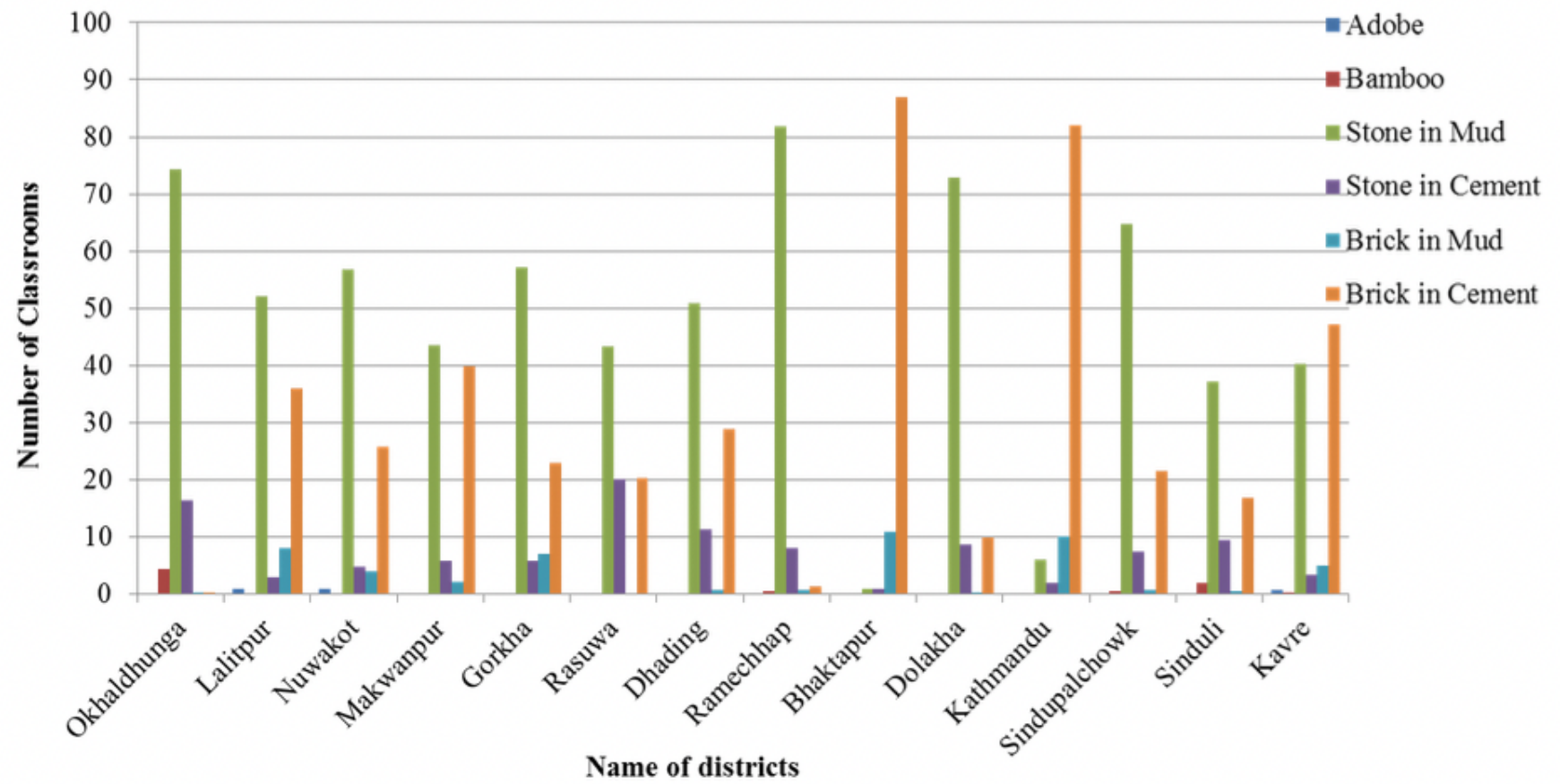

Figure 13

Type of wall construction in 14 districts 


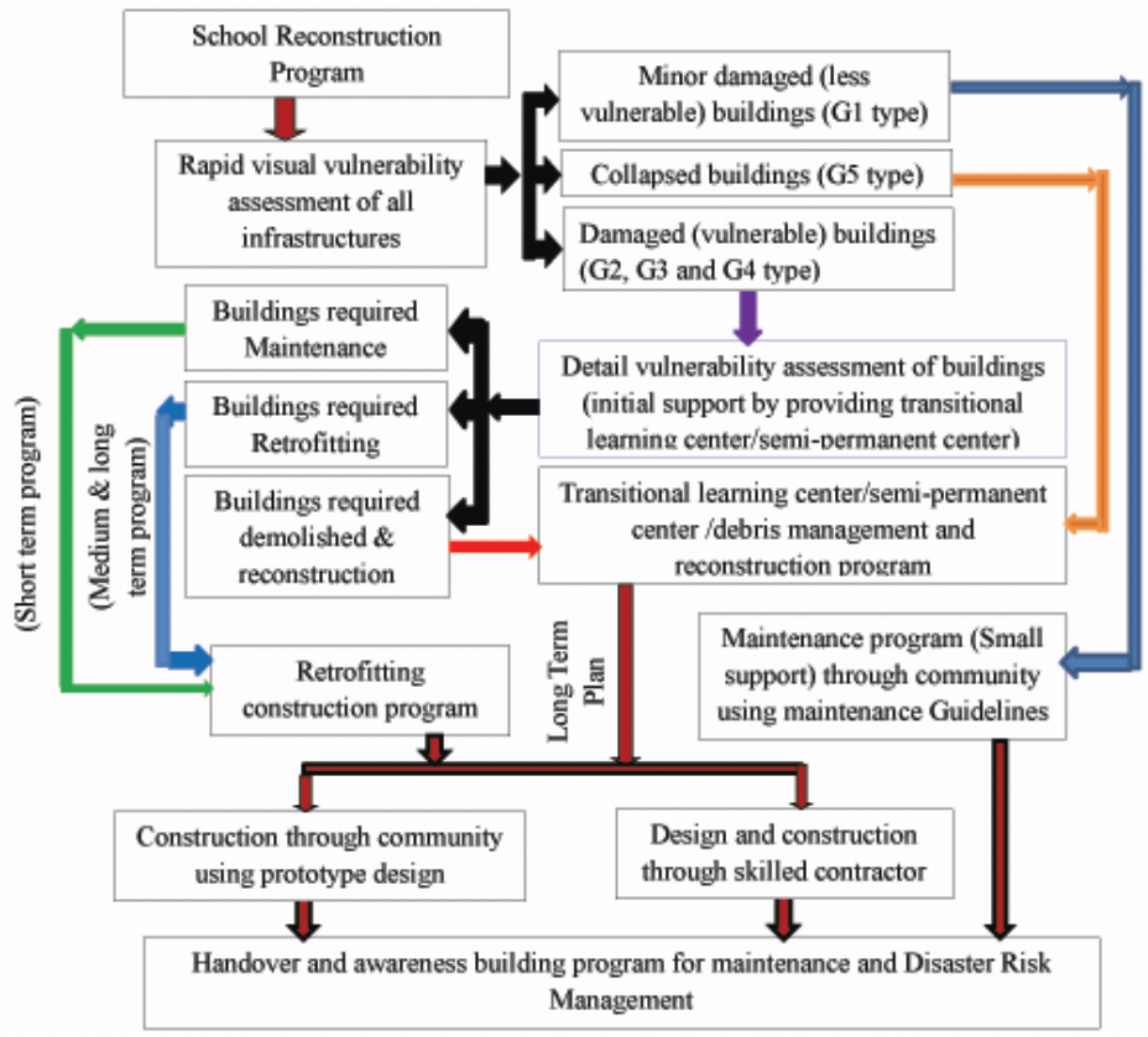

Figure 14

Proposed plan for reconstruction of school buildings after 2015 Gorkha Earthquake in Nepal 